\title{
O CAMPO PRESENTE, IMPROVÁVEL E PRÓXIMO
}

\author{
Juliana Pondé Fonseca*
}

SumÁrio: 1. A lógica da EXCEÇÃo. 2. O CAMPo. 3. CAMPOS PRESEnTES. 4. CAMPoS IMPROVÁVEIS. 5. CAMPO LOCAL. 6. CONSIDERAÇÕES “FINAIS”. 7. REFERÊNCIAS.

\section{RESUMO}

A partir do pensamento de Giorgio Agamben acerca do estado de exceção e de sua materialização, os campos, é possível perceber que a exceção de fato se torna a regra. Os campos não são figuras que pertencem ao passado, pois podem ser encontrados no tempo presente e em locais muito improváveis, como um estádio de futebol, um hotel nos arredores de Paris, um condomínio fechado nos Estados Unidos e até mesmo num terreno no bairro do Boqueirão, em Curitiba. Esses locais assemelham-se aos campos, mesmo que temporariamente, e indicam a atuação de uma ordem jurídica que se funda e se mantém na própria suspensão.

Palavras-chave: estado de exceção; campos; presente.

\section{A LÓGICA DA EXCEÇÃ̃o}

A relação essencial entre soberania e estado de exceção foi apontada por Carl Schmitt em 1922, como ressalta Agamben. O soberano seria aquele que decidiria sobre o estado de exceção, figura que tentaria incluir no direito a sua própria suspensão, mas que na verdade é uma zona de indeterminação, nem interior nem exterior ao ordenamento jurídico. ${ }^{1}$

\footnotetext{
* Mestranda do Programa de Pós-Graduação em Direito da UFPR. E-mail: jujufonseca@gmail.com

${ }^{1}$ AGAMBEN, Giorgio. Estado de exceção. Trad. Iraci D. Poleti. São Paulo: Boitempo, 2004, p. 11-12, 38-39.
} 
O conceito schmittiano de soberania é um conceito-limite, que permite descobrir a essência da política. Soberania, aqui, não deve ser entendida como um conceito interno, concernente ao monopólio da violência ou à existência de um povo, nem como um conceito externo, que diz respeito ao reconhecimento de um Estado por outros Estados. É um conceito que opera negativamente, pois a norma só pode ser compreendida através de sua exceção. ${ }^{2}$ A exceção, a suspensão da norma, na verdade a constitui.

Paradoxalmente, o direito parece só poder existir capturando a anomia, o nãodireito. Ao mesmo tempo em que a zona de anomia deve ser mantida em relação com o direito, deve ser libertada dessa relação. ${ }^{3}$

Agamben relata o debate travado entre Schmitt e Walter Benjamin acerca do estado de exceção entre 1929 e 1956. Schmitt vê o estado de exceção como algo essencialmente temporário e transitório. ${ }^{4}$ Entretanto Benjamin revela, em sua oitava tese sobre a história, que o estado de exceção é a regra. ${ }^{5}$ Se o estado de exceção visa tornar a norma aplicável suspendendo temporariamente sua eficácia e, dessa forma, é a base do funcionamento de toda a ordem jurídica, o que fazer se exceção e regra se confundem? Quando a exceção vira a regra, a regra desaparece. Mas quando a regra desaparece, a exceção desaparece também. ${ }^{6}$

Embora desconcertante, esse é o contexto político contemporâneo. Vive-se sob a lógica da exceção. É através dela que o direito se refere à vida, é essa lógica que define a relação das pessoas com o direito. ${ }^{7} \mathrm{E}$ ao analisar a exceção, encontra-se com o

${ }^{2}$ DIKEN, Bülent; LAUSTEN, Carsten Bagge. The culture of exception: sociology facing the camp. Londres: Taylor and Francis e-library, 2005, p. 18-19.

${ }^{3}$ AGAMBEN, op. cit., p. 92.

${ }^{4}$ Ibidem, p. 90.

${ }^{5}$ BENJAMIN, Walter. Sobre o conceito de história. In: Magia e técnica, arte e política: ensaios sobre literatura e história da cultura. 4. ed. São Paulo: Brasiliense, 1985. p. 226.

${ }^{6}$ DIKEN; LAUSTEN, op. cit., p. 7.

${ }^{7}$ AGAMBEN, op. cit., p. 92 
campo. "O campo é a exceção encarnada". ${ }^{8}$ Em tempos de exceção-como-regra, a sociedade se organiza de acordo com a idéia de campo.

Essa afirmação carece de exemplos e explicações. Se o campo permeia toda a sociedade atual, é preciso ao menos apontar sinais de tal fenômeno. O campo, na verdade, está mais presente que se imagina, está nos lugares mais improváveis e também está mais próximo do que se quer acreditar. Essa é a tarefa que será intentada nas páginas a seguir.

\section{O CAMPO}

Em Means without end, Agamben continua investigando os temas expostos em seus outros trabalhos. Como adverte o próprio autor, ${ }^{9}$ os fragmentos devem ser interpretados na perspectiva da obra completa (Homo sacer) e atentando para o objetivo de repensar todas as categorias de nossa tradição política sob a luz da relação entre vida nua e poder soberano. Os fragmentos, portanto, complementam e aprofundam a reflexão.

Em “O que é um campo?”, ele pretende caminhar numa direção oposta à tradicional, que define o campo a partir dos eventos que aconteceram em seu interior, para evitar que se trate o objeto de estudo como um fato histórico, pertencente ao passado. O campo é a "matriz escondida e o nomos do espaço político em que ainda vivemos" 10 e existe no tempo presente.

Inicialmente, analisa-se a origem dos campos. Os primeiros teriam surgido em

\footnotetext{
${ }^{8}$ Tradução livre de: "The camp is the exception incarnated". DIKEN; LAUSTEN, op. cit., p. 18-19.

${ }^{9}$ AGAMBEN, G. Means without end. Minneapolis: University of Minnesota Press, 2000, prefácio.

${ }^{10}$ Tradução livre de: "the hidden matrix and nomos of the political space in which we still live". Ibidem, p. 37.
} 
Cuba, em 1896, criados pelos espanhóis para conter a população insurreta da colônia; ou nos campos em que os ingleses teriam isolado os bôeres no início do século XX (há certa controvérsia entre os historiadores quanto ao tema). Entretanto, o mais importante é a análise da estrutura político-jurídica dos primeiros campos: eles surgiram da lei marcial e do estado de exceção e não do direito ordinário. O mesmo se deu com os campos nazistas juridicamente baseados no instituto Schutzhaft (prisão protetora ${ }^{11}$ ), fundado nas leis prussianas de estádio de sítio (1851) e de proteção da liberdade pessoal (1850), ambas largamente utilizadas durante a Primeira Guerra Mundial. Esse instituto era considerado pelos nazistas uma medida preventiva, que consistia na prisão de indivíduos que não haviam cometido crime algum, com o objetivo de resguardar a segurança do Estado. ${ }^{12}$

"O campo é o espaço que se abre quando o estado de exceção começa a se tornar a regra". ${ }^{13}$ Hoje, o campo funciona em circunstâncias normais, pois o estado de exceção sobre o qual ele se funda permanece, e ele começa a se fazer presente nos locais mais improváveis.

O primeiro campo nazista, Dachau, foi criado em 1933 e colocado fora da ordem jurídica. Mas não foi, e nem os campos de hoje o são, um mero espaço externo, pois o que é excluído no campo é incluído por sua própria exclusão. ${ }^{14}$ É essa a particular estrutura político-jurídica dos campos, que permite a compreensão do que aconteceu (e acontece) em seu interior: nele a lei é totalmente suspensa, o que faz com que surja um espaço aonde tudo é possível e aonde se confundem dentro e fora, lícito e ilícito, exceção e regra. ${ }^{15}$

${ }^{11}$ Em inglês, protective custody. Preferiu-se o vocábulo prisão ao invés de custódia, que é mais utilizado no português.

${ }^{12}$ Ibidem, p. 38-39.

${ }^{13}$ Tradução livre de: "The camp is the space that opens up when the state of exception starts to become the rule", grifos no original. Ibidem, p. 39.

${ }^{14}$ Ibidem, p. 40.

${ }^{15}$ Ibidem, p. 40-41. 
O campo é o espaço biopolítico ${ }^{16}$ por excelência, pois seus habitantes não têm quaisquer direitos nem status político. São reduzidos à vida nua e qualquer ato cometido contra eles não é considerado crime.

Se o campo é a materialização do estado de exceção, é preciso admitir que estamos diante dele "virtualmente todas as vezes em que tal estrutura é criada, não importando a natureza dos crimes nela cometidos e nem a denominação ou topografia específica que possa ter". ${ }^{17}$

A estrutura do Estado-nação, que antes poderia ser definida por três elementos - território (um local determinado), Estado (determinado ordenamento) e nascimento passa por uma ruptura que acontece não no Estado ou no território mas no local aonde a vida nua é inscrita em seus interiores. ${ }^{18} \mathrm{O}$ campo é o sinal de que o sistema não pode funcionar sem se tornar uma máquina letal e demonstra que entre a vida nua e o Estado-nação há um vazio em contínuo crescimento. Ao mesmo tempo em que a vida nua não pode ser inscrita no ordenamento, ela o é, pois habita o campo.

"A um ordenamento sem localização (isto é, o estado de exceção durante o qual a lei é suspensa) corresponde agora uma localização sem ordenamento (isto é, o campo como um espaço permanente de exceção)". ${ }^{19}$ O sistema político ao mesmo tempo contém e é excedido pela "localização deslocante" que é o campo. Ele se une à tríade Estado-território-nascimento e acaba por despedaçá-la.

\section{CAMPOS PRESENTES}

${ }^{16}$ Biopolítico aqui é utilizado no sentido mencionado por Agamben, que difere do sentido foucaultiano. Para Foucault, a biopolítica surge no século XIX, quando o poder passa a se ocupar da vida. Para Agamben, a biopolítica existe desde os tempos mais remotos, pois a produção do corpo biopolítico é a atividade mais autêntica do poder soberano. DIKEN; LAUSTEN, op. cit., p. 44.

${ }^{17}$ Tradução livre de: “... we will then have to admit to be facing a camp virtually every time that such a structure is created, regardless of the nature of the crimes commited in it and regardless of the denomination and specific topography it might have." AGAMBEN. Means..., p. 41-42.

${ }^{18}$ Ibidem, p. 43.

${ }^{19}$ Tradução livre de: "To an order without localization (that is, the state of exception during which the law is suspended) corresponds now a localization without order (that is, the camp as a permanent space of exception)". Ibidem, p. 44. 
Além dos campos de concentração nazistas, também a pista de ciclismo na França onde autoridades do governo de Vichy reuniram os judeus antes de entregá-los aos alemães e o campo de refugiados criado em Collioure durante a guerra civil espanhola podem ser considerados verdadeiros campos. ${ }^{20}$ Entretanto e conforme mencionado, os campos não são fatos históricos, não são figuras no tempo passado. Agamben dá ricos exemplos de campos contemporâneos. ${ }^{21}$

Os prisioneiros da base norte-americana de Guantánamo são desprovidos de estatuto jurídico e essa sua condição foi inserida no ordenamento pelo USA Patriot Act de 2001. Não possuem nem o status de prisioneiro de guerra, conforme estabelecido pela Convenção de Genebra: são objetos de uma detenção indeterminada tanto no tempo como na sua natureza (fora da lei e fora do controle do judiciário). ${ }^{22}$ Os presos são mantidos em celas pequenas (menos de 6 metros quadrados de área), com paredes de redes de arame e chão de cimento. A luz elétrica permanece ligada 24 horas por dia. Não há, portanto, possibilidade de descanso ou privacidade. Por estarem fora do território norte-americano, não dispõem de nenhuma das garantias concedidas pelo ordenamento do país. Depoimentos dos presos, geralmente mantidos sob anonimato, falam das práticas de tortura, que envolvem desde maus tratos físicos a abuso sexual. Prisioneiros são forçados a lamberem sapatos ou excrementos e a se comportarem como animais. "Estando ao mesmo tempo dentro e fora dos EUA, o Campo Delta é efetivamente uma zona de indistinção criada através da suspensão da lei". ${ }^{24}$

Em agosto de 1991, o navio Vlora chegou à cidade de Bari, no sul da Itália,

${ }^{20}$ Ibidem, p. 42. O autor menciona que o poeta espanhol Antonio Machado morreu em Collioure, França, em 1939.

${ }^{21}$ Tentativas de trazer o pensamento de Agamben para o presente não são anacrônicas. $\mathrm{O}$ autor sempre está preocupado com temas atuais e muitos exemplos desse ponto são mencionados por ele. Para uma manifestação de Agamben sobre problemas contemporâneos, ver Non au tatouage biométrique, em que ele critica a obrigatoriedade dos visitantes dos EUA a terem suas impressões digitais escaneadas ao entrarem no país.

${ }^{22}$ AGAMBEN. Estado de exceção ..., p. 14.

${ }^{23}$ DIKEN; LAUSTEN, op. cit., p. 29-34.

${ }^{24}$ Tradução livre de: "Being both inside and outside the USA at the same time, Camp Delta is effectively a zone of indistinction created through the suspension of the law". Ibidem, p. 29. 
trazendo como passageiros milhares de imigrantes ilegais albaneses. Todos foram transportados em ônibus da rede de transportes municipal para o Stadio della Vittoria (um estádio de futebol). ${ }^{25}$ Do dia 6 ao dia 14 daquele mês, os albaneses ficaram presos no estádio, sem qualquer assistência médica e sujeitos ao calor e ao sol forte do verão italiano. A pouca comida que receberam lhes foi lançada do alto de gruas ou helicópteros. A cena guarda uma desagradável semelhança com o ato de alimentar animais. ${ }^{26}$ Aqueles que tentaram escapar foram violentamente reprimidos pela polícia e pelo exército. No dia 14, foram quase todos enviados de volta à Albânia em aviões do exército italiano.

As zones d'attente ${ }^{27}$ (zonas de espera) francesas foram legalizadas pela lei Quilès, de 1992, após uma lei de conteúdo similar ter sido considerada inconstitucional pelo Conselho Constitucional pela insuficiência das garantias previstas. São espaços localizados nos portos e aeroportos, ou próximos a eles, ${ }^{28}$ destinados a manter aqueles cuja autorização para entrar no país foi negada ou que requisitaram asilo e aguardam a avaliação preliminar do pedido (confirmam se não é manifestamente infundado). Uma outra lei de 1994 complementou a primeira, criando zonas nas estações ferroviárias e prevendo a retenção de passageiros em trânsito cuja entrada na França ou no destino final foi recusada. O tempo de retenção ${ }^{29}$ é de 48 horas, prorrogáveis por mais 48 . Após isso, a administração não pode mais prorrogá-la sem consultar o judiciário. $\mathrm{O}$ juiz, por sua vez, pode determinar a prorrogação por outros oito dias. "Excepcionalmente" pode haver nova prorrogação de oito dias, determinada pelo mesmo juiz. Portanto, é possível permanecer nas zones d'attente por até vinte dias,

${ }^{25} \mathrm{O}$ exemplo é mencionado por AGAMBEN em (Means without end ..., p. 42).

${ }^{26}$ Um documentário de curta duração a respeito do episódio pode ser visualizado pela Internet. Disponível em <http://www.youtube.com/watch?v=So31xBTGlFw〉.

${ }^{27}$ Outro exemplo mencionado por AGAMBEN, op. cit., loc. cit.

${ }^{28}$ Alguns hotéis próximos ao aeroporto de Paris são utilizados como zonas de espera.

${ }^{29}$ O termo correto é retenção (rétention) ou manutenção (maintien), pois o termo detenção (détention) é reservado, no direito francês, à privação de liberdade levada à cabo em estabelecimentos penitenciários. JULIEN-LAFFERRIÈRE, François. La rétention des étrangers aux frontières françaises. Cultures \& Conflits, 23. Disponível em: <http://www.conflits.org/index346.html>. Acesso em: 4 set. 2009. 
numa situação indefinida. Algumas garantias são concedidas aos retidos, mas na prática muitas são ineficazes. Há a previsão de recurso contra a decisão de prorrogação, mas ele não possui efeito suspensivo e provavelmente não será julgado antes dos vinte dias. O direito de comunicação encontra obstáculos, pois os retidos só têm acesso a cabines telefônicas pagas no interior das zonas. Aqueles que não podem pagar ficam incomunicáveis. Também é previsto o direito a receber visitas, porém como não existem que o regulamentem, elas ficam a critério dos oficiais administrativos, que decidem quais são os visitantes apropriados e a duração de cada visita. $^{30}$

Ao redor do mundo, campos de refugiados demonstram a crise da idéia de direitos humanos. Os direitos dos refugiados não podem ser concebidos como direitos de cidadãos de um determinado Estado e, por isso, restam totalmente desprotegidos. Direitos que supostamente são sagrados e inalienáveis são deixados sem qualquer proteção e aqueles que em tese seriam a própria personificação da idéia de direitos humanos são, na verdade, o símbolo de seu fracasso. ${ }^{31}$

Um dos detidos no campo de Woomera, na Austrália, afirmou não acreditar estar neste país ao adentrar o campo. As coisas que lá aconteceram não poderiam acontecer na Austrália. Partindo disso, o detento chega à conclusão que Woomera deveria ser um outro país. Woomera era, na verdade, uma zona de indistinção entre dentro e fora, entre direito e não-direito. O centro de detenção foi criado em 1999 para lidar com o crescente número de imigrantes ilegais. Apesar de ter capacidade para receber 400 detentos, em abril de 2000 abrigava aproximadamente 1500 pessoas. Os refugiados realizaram greves de fome, praticaram auto-mutilação, enforcaram-se no arame farpado que cercava o campo, beberam xampu e cavaram seus próprios túmulos. Os funcionários do campo o descreveram como uma "zona de guerra". Woomera foi fechado em abril de $2003 .{ }^{32}$

\footnotetext{
${ }^{30}$ Ibidem, loc. cit.

${ }^{31}$ AGAMBEN. Means..., p. 19-20.

${ }^{32}$ DIKEN; LAUSTEN, op. cit., p. 81-82.
} 
A prefeitura de Hanstholm, na Dinamarca, subitamente parou de pagar a ajuda de custo normalmente fornecida aos refugiados em julho de 2002, pois alguns haviam se recusado a participar de aulas de dinamarquês. Os refugiados vivem no campo de mesmo nome da cidade e a ajuda de custo é sua única fonte de renda. Após uma reclamação, realizada pelos próprios refugiados, a mídia foi envolvida. O ministro dos "Refugiados, imigrantes e integração" explicou que a prefeitura não sabia que os imigrantes não eram obrigados a participar das aulas em questão e que os pagamentos seriam efetivados retroativamente. A justificativa dos atos ilegais da prefeitura foi, portanto, ignorância da lei e nenhuma ação foi tomada em relação à ilegalidade. ${ }^{33}$

Viver em campos como o de Hanstholm e receber uma ajuda de custo estatal é a única alternativa dos refugiados na Dinamarca. Se deixam os campos, a ajuda de custo cessa e eles perdem o direito de usar o sistema de saúde do país (o mesmo acontece com refugiados na Áustria). ${ }^{34}$ E esse é o tratamento reservado àqueles cujo pedido de asilo foi aceito. Os que tiveram seu pedido recusado são encaminhados a centros de detenção e posteriormente enviados a seus países de origem.

O campo de Sandholm é um desses centros de detenção. O relato de $\mathrm{H}$. Elmess, libanesa, que teve seu pedido recusado e aguarda ser enviada de volta ao seu país, sobre a vida no campo:

Eu não sinto mais nada. Nenhuma esperança. Nenhuma fome. Eu só quero um pouco de paz. Antes eu chorava o tempo todo, sentia falta da minha liberdade, sentia falta dos meus filhos, agora eu não me importo... Hora de comer, gritam os funcionários às 12. Hora de comer, eles gritam de novo às 17. Às 22 nós vamos para a cama. É o mesmo todos os dias. Tanto faz voltar ao Líbano e ser morta. Por dentro eu já estou morta... eu não sou nada. ${ }^{35}$

${ }^{33}$ Ibidem, p. 82.

${ }^{34}$ Ibidem, p. 88.

${ }^{35}$ Tradução livre de: "I feel nothing anymore. No hope. No hunger. I just want some peace. Formerly I cried all the time, I missed my freedom, I missed my children, now I am just unconcerned... Eating time, shout the personnel at 12. Eating time, they shout again at 17. At 22 we go to bed. It is the same every single day. I can just as well go back to Lebanon and get killed. Inside I am already dead. I am nothing". Ibidem, p. 91. 
Se os direitos de Elmess existem, eles não recebem qualquer proteção. No momento em que seu pedido de asilo foi recusado, até os parcos direitos concedidos aos refugiados na Dinamarca lhe foram retirados. ${ }^{36}$

Nos campos, a vida do refugiado é extremamente regulada e restringida pela lei. O refugiado está radicalmente no interior do ordenamento, mas ao mesmo tempo está desprotegido, desprovido de direitos e portanto fora dele. O refugiado é incluído ao ser excluído e excluído ao ser incluído ${ }^{37}$ Figura paradoxal, certamente, mas não por isso menos simbolizadora de tempos contemporâneos.

\section{CAMPOS IMPROVÁVEIS}

Para Agamben, as gated communities norte-americanas podem se assemelhar a campos e em alguns momentos, nesses locais, surge uma zona de indeterminação entre vida nua e vida política. ${ }^{38}$

Gated communities são, na verdade, condomínios fechados. A associação entre os campos mencionados e locais onde impera o luxo e a abundância pode parecer improvável, mas revela aspectos importantes acerca do cenário político contemporâneo e foi exposta pelos autores ingleses Diken e Lausten na obra The culture of exception: sociology facing the camp.

${ }^{36}$ Impossível não notar certa semelhança entre o muçulmano dos campos de concentração nazistas - "cadáveres ambulantes", figura limítrofe entre humano e não-humano - e as palavras de Elmess. Certamente há relação entre ambos, a começar pelo fato de serem habitantes do campo. Mas o quão profunda seria essa relação é um problema de maior complexidade, que poderia por si só ser objeto de extensa investigação. Pára-se por aqui, portanto, apenas apontando o inevitável questionamento. Para mais sobre o muçulmano, ver AGAMBEN. O que resta de Auschwitz: o arquivo e a testemunha. Trad. Selvino J. Assmann. São Paulo: Boitempo, 2008, p. 49-91, p. 163-169.

\footnotetext{
${ }^{37}$ DIKEN; LAUSTEN, op. cit., p. 80.

${ }^{38}$ AGAMBEN. Means..., p. 42.
} 
Entre os exemplos mencionados por Diken e Lausten está Haverleij, um condomínio fechado na Holanda. Ocupa uma ilha inteira, conectada ao continente por uma única ponte. O local se assemelha a um forte: cercado por muros altos, monitorado por câmeras de vídeo, patrulhado por vários seguranças. A publicidade do condomínio anuncia que lá dentro se pode viver como um príncipe. Ainda assim, as semelhanças com um estabelecimento prisional são grandes. Do interior dos muros, a cidade lá fora mais parece uma selva urbana, onde reina o terror. É a materialização da obsessão contemporânea com a segurança. ${ }^{39}$

Embora o fato de Haverleij se localizar numa ilha impressione, o exemplo mais forte de gated community-campo é o condomínio Celebration, na Flórida, Estados Unidos. Foi desenvolvido pela Walt Disney Company e localiza-se ao lado do famoso parque temático. Procura recriar uma cidade norte-americana do século XIX, onde antagonismos não existem, nem preocupações acerca da segurança. ${ }^{40}$

Todos os aspectos de uma perfeita micro-sociedade são cuidadosamente planejados. Nada acidental acontece pois tudo é padronizado. Os moradores não podem trocar a cor de suas casas nem das cortinas (obrigatoriamente brancas), não podem alterar seus jardins perfeitamente planejados, nos quais a grama deve ser regularmente cortada, não escolhem onde estacionam seus carros. Há uma escola no interior do condomínio, freqüentada pelos filhos dos moradores. A iniciativa Disney controla o currículo escolar. Ao se mudar para Celebration, não se compra só uma casa (um terço mais cara que um imóvel similar nas proximidades), adota-se um novo estilo de vida. ${ }^{41}$

Um dos diretores da iniciativa afirma que o rígido regulamento do condomínio na verdade liberta os moradores, lhes dá segurança. Mas essa ilusão de segurança tem alto preço, pois as ameaças do mundo exterior se transformam em conformismo obrigatório no interior. Os moradores que reclamam da administração são taxados de

\footnotetext{
${ }^{39}$ DIKEN; LAUSTEN, op. cit., p. 91-92.

${ }^{40}$ Ibidem, p. 92.

${ }^{41}$ Ibidem, p. 93.
} 
"Negativos" ("Negatives") e são encorajados a deixar Celebration. Eles são liberados do cumprimento de seus contratos, com a condição de jamais revelarem as razões que os levaram a sair. ${ }^{42}$

Essas gated communities fazem parte de um processo de privatização: seus habitantes não freqüentam espaços públicos e geralmente não existem nem espaços de convivência entre os moradores. Mas ao mesmo tempo, esses condomínios geralmente fazem parte de um município, estão dentro e fora da cidade, numa zona de indistinção. ${ }^{43}$ A auto-segregação não deixa de ser um processo de negação da cidade, ao mesmo tempo que depende dela. ${ }^{44}$

O mais surpreendente é que, nos Estados Unidos, muitas vezes os moradores das gated communities lidam com a criminalidade independentemente da polícia. Um morador afirma que "civis podem lidar com o crime mais facilmente porque não somos impedidos por restrições constitucionais como a polícia. Nós podemos deitar e rolar". ${ }^{45}$ Os moradores acabam agindo como uma gangue justiceira que não encontra limites. Novamente, esses condomínios revelam uma zona de indistinção: quando algum dos moradores precisar de garantias concedidas pelo ordenamento, estará dentro dele. Mas o "criminoso" não tem direito a nenhuma garantia, está à mercê dos moradores justiceiros. Dentro e fora da lei convivem e os limites entre eles restam borrados.

Tanto os campos como as gated communities funcionam dentro da mesma lógica: a lógica da exceção. São locais de suspensão do tempo e do espaço, excluídos e incluídos simultaneamente. A sociedade parece produzir dois tipos de campos: em

${ }^{42}$ Ibidem, loc. cit.

${ }^{43}$ Ibidem, p. 94.

${ }^{44}$ O tema é muito discutido entre arquitetos e urbanistas. FREY, Klaus; DUARTE, Fábio. Auto-segregação e a gestão das cidades. Disponível em: <http://erevista.unioeste.br/index.php/ccsaemperspectiva/ article/download/1422/1154>. Acesso em: 29 ago. 2009.

45 Tradução livre de: "civilians can deal with crime more easily because we are not hampered by constitutional restrictions like the police. We can slam and jam". DIKEN; LAUSTEN, op. cit., p. 94. 
alguns, a entrada é livre mas a saída é bloqueada, e em outros a entrada é bloqueada e a saída é livre. Uns são construídos para manter pessoas dentro, outros para manter pessoas fora. ${ }^{46}$ Enquanto os habitantes de alguns campos abandonam a sociedade, os de outros são abandonados por ela.

O número de campos e de pessoas segregadas neles cresce de forma incontrolável. Embora a segregação possa ser voluntária ou forçada, os campos contemporâneos aparecem como gêmeos, não idênticos, mas ainda assim gêmeos. Eles dividem a lógica da exceção e expressam simultaneamente convergência e divergência, uma zona nebulosa que não pode ser contida na cidade, transformando-a em espaço descontínuo. ${ }^{47}$

\section{CAMPO LOCAL}

Embora as favelas em geral assemelhem-se a campos, ${ }^{48}$ um local específico na cidade de Curitiba chama a atenção por sua paradoxalidade.

Trata-se de um terreno de 1.443 metros quadrados no bairro do Boqueirão, na esquina das ruas José Maurício Higgins e Brasil para Cristo, localizado entre residências e indústrias leves. No local havia anteriormente um barracão pertencente à massa falida da empresa Tecnicom, abandonado desde 1997. Em 1999, o barracão foi ocupado por 30 famílias de catadores de materiais recicláveis, que desconheciam a titularidade do imóvel. Utilizavam o local para armazenar os materiais e para morar.

Somente em maio 2004 a síndica da massa falida requer a desocupação do imóvel nos autos do processo de falência. O pedido é negado pela necessidade de proposição de ação específica. Em setembro do mesmo ano, é proposta ação de

\footnotetext{
${ }^{46}$ DIKEN; LAUSTEN, op. cit., p. 96.

${ }^{47}$ Ibidem, p. 147.

${ }^{48}$ Ibidem, p. 9.
} 
reintegração de posse com pedido de tutela antecipada. ${ }^{49} \mathrm{O}$ Ministério Público se manifestou favoravelmente à antecipação e em outubro a medida liminar foi concedida. ${ }^{50}$

Os moradores não foram citados nem tomaram conhecimento do processo. A juíza da $6^{\mathrm{a}}$ Vara Cível, onde tramita a ação, requer que a FAS - Fundação de Ação Social do município de Curitiba acompanhe o processo e auxilie os moradores. A fundação nada responde. Somente em setembro de 2005 o município se manifesta, após ter sido intimado na pessoa de seu Procurador-Geral, mas afirma que a FAS não considera de sua competência acompanhar despejos e que a COHAB - Companhia de Habitação Popular de Curitiba não tem legitimidade para atuar em ação concernente à imóvel particular.

Os moradores só são citados em junho de 2006 e contestam, apresentando exceção de usucapião especial coletiva de imóvel urbano, com base na Constituição e no Estatuto da Cidade. Para tanto, os moradores receberam auxílio da Terra de Direitos, organização de direitos humanos. Somente em janeiro de 2007 a juíza aprecia a exceção, mas apenas para extingui-la sem julgamento de mérito. A apelação dos catadores foi parcialmente provida e o Tribunal de Justiça determinou que a exceção deveria ser apreciada na sentença da ação de reintegração.

Um incêndio destruiu o barracão e todas as casas em fevereiro de 2007. Em junho de 2008 foi realizada audiência de conciliação, na qual foi determinada a expedição de ofícios para a COHAB-CT, para a COHAPAR - Companhia de Habitação do Paraná e Ministério das Cidades, os responsáveis, respectivamente nas esferas municipal, estadual e federal, por programas de habitação popular.

Em agosto de 2008 a COHAPAR respondeu ao ofício, informando que não existem projetos de regularização fundiária previstos para auxiliar os catadores e que

${ }^{49}$ Autos n ${ }^{\mathrm{o}} 1.170 / 2004,6^{\mathrm{a}}$ Vara Cível de Curitiba.

${ }^{50}$ Note-se que a concessão de liminar sem a oitiva do réu, nos termos do art. 928 do CPC, só poderia ter sido concedida se a ação tivesse sido proposta dentro de ano e dia da turbação ou esbulho (art. 924 do CPC). A concessão, aqui, violou o devido processo legal e os princípios da ampla defesa e do contraditório. 
recursos não foram direcionados para esse fim. Em dezembro do mesmo ano, o Ministério das Cidades e a COHAB dão respostas semelhantes. A COHAB, porém, afirmou que iria incluir a área em seu planejamento para o ano de 2009.

A COHAB se reuniu com as famílias e afirmou que até maio de 2009 elas seriam atendidas por projetos habitacionais. Em julho de 2009, somente sete famílias haviam sido transferidas para um conjunto habitacional. Além disso, a empresa pública informou a Terra de Direitos que os catadores não estão incluídos nos projetos financiados com os recursos do programa Minha Casa Minha Vida. ${ }^{51}$

Em agosto de 2009, teria sido realizada já uma segunda praça (a primeira teria sido finalizada sem arrematantes) para leilão do terreno se não houvessem sido opostos embargos de terceiro. Foi concedida uma ordem liminar que suspendeu o leilão, pois do edital não constava o pedido de usucapião sobre o imóvel.

As famílias constituíram a Associação de Catadores e Catadoras de Materiais Recicláveis Sociedade Barracão, incluída no projeto ECO Cidadão da Prefeitura de Curitiba. $^{52}$ Também foi construído um centro de separação de recicláveis, com o auxílio do município. Mesmo atuando de forma organizada, as famílias geralmente lucram apenas um salário mínimo por mês.

As condições são precárias: as habitações estão em péssimas condições, água e luz são clandestinas. Traficantes de drogas se instalaram em meio à comunidade e ditam as regras do local. Em agosto de 2009 uma moradora foi expulsa de sua casa para que esta e todos os seus pertences fossem vendidos pelos traficantes a uma outra família. Uma pessoa foi morta no local. Os moradores têm medo de represálias e por isso se mantêm em silêncio. A COHAB, porém, contatou a Secretaria de Segurança Pública e a Guarda Municipal a respeito do problema. Nada foi feito.

${ }^{51}$ O Projeto Minha Casa Minha Vida foi instituído pela Lei Federal $n^{\text {o }} 11.977 / 2009$ e tem como meta a construção de um milhão de moradias para famílias com renda mensal inferior a dez salários mínimos. seletiva.

${ }^{52}$ Projeto de inclusão dos catadores de materiais recicláveis no sistema público de coleta 
Apesar de todas as condições adversas, as famílias permanecem no local por ele proporcionar não só a atividade de coleta de materiais recicláveis mas também o acesso das crianças à rede pública de ensino: existem duas escolas públicas e uma creche nas proximidades, além de duas unidades municipais de saúde.

A Terra de Direitos discute com a COHAB a possibilidade de compra do terreno, valendo-se recursos federais. Para tanto, tem procurado incluir a associação em programas como o Minha Casa Minha Vida ou o FNHIS (Fundo Nacional de Habitação de Interesse Social). Mas o fato de o terreno pertencer a uma massa falida dificulta o levantamento dos recursos.

Entre residências e estabelecimentos industriais, o espaço ocupado pelos moradores contrasta com o seu entorno. Está separado da cidade, mas ao mesmo tempo pertence a ela. Os moradores conseguem usufruir de certos serviços públicos, como saúde e educação, e prestam um serviço de extrema utilidade para a cidade. Mas ao mesmo tempo, a polícia não interfere no que acontece em seu interior.

O local ocupado pelas famílias de catadores assemelha-se a um campo. Como os demais campos, é uma zona de indistinção entre direito e não-direito. Primeiro, pois no interior da comunidade vigoram as regras dos traficantes e não o ordenamento brasileiro. Os moradores vivem sob medo e não acreditam na possibilidade de serem protegidos pela polícia. Segundo, porque a associação procura obter a tutela jurisdicional dos direitos previstos pelo ordenamento mas não encontra qualquer proteção. Consegue apenas evitar que a situação se torne pior do que está (como no caso da decisão liminar que suspendeu o leilão). Diferentemente daqueles que estão nos campos de refugiados mencionados anteriormente, podem ir ao judiciário e pleitear seus direitos, mas essa diferença parece não importar. Os direitos pleiteados não são efetivados e enquanto não o forem, existem sem existir de fato.

Agamben afirma que o conceito de povo abrange tanto o sujeito político constitutivo como uma classe de pessoas que é excluída de fato ou de direito da política. Há uma oscilação dialética entre o Povo, corpo político integral e o povo, multiplicidade de corpos excluídos. De um lado, temos um conceito que pretende 
incluir a todos e do outro, a exclusão dos oprimidos. ${ }^{53}$ Os moradores membros da comunidade Barracão representam o povo e revelam a polaridade do conceito. Em tese, fazem parte do corpo político integral, porém são excluídos da política: "pobreza e exclusão não são somente conceitos econômicos e sociais mas também categorias eminentemente políticas". 54

\section{CONSIDERAÇÕES "FINAIS"}

Os campos estão cada vez mais freqüentes, mais próximos, mais improváveis. A lógica da exceção opera nos locais menos esperados e comprova-se que, de fato, hoje a exceção é a regra.

O pensamento de Agamben é crucial para a compreensão da política contemporânea. Sem entender o estado de exceção, muitos dos fenômenos causados por ele passam despercebidos, ou, no mínimo, não são percebidos como o que são: não “exceções”, casualidades ou meros efeitos colaterais. São manifestações daquilo que a política e, porque não, o direito atuais realmente são.

Um hotel nos arredores de Paris, um estádio de futebol na Itália, campos de refugiados na Dinamarca, um condomínio fechado nos Estados Unidos, um terreno no bairro do Boqueirão, em Curitiba: em todos esses locais, aparentemente banais, surge um espaço de suspensão do direito. Atrocidades podem ser cometidas no interior desses espaços, e essa possibilidade não depende do direito. Depende, no máximo, da boa vontade da força policial local, quando depende. São espaços que se assemelham aos campos, mesmo que só em momentos determinados. E nesses momentos, direito e não-direito confundem-se e se indeterminam mutuamente.

${ }^{53}$ AGAMBEN. Means..., p. 29-31.

${ }^{54}$ Tradução livre de: "poverty and exclusion are not only economic and social concepts but also eminently political categories." Ibidem, p. 33. 
A formação de "leis próprias" no interior de favelas ou espaços como o ocupado pela comunidade Barracão é encarada geralmente como situação de pluralismo jurídico, no qual vigoram simultaneamente mais de uma ordem jurídica. A relação entre as duas ordens seria a de vigência em paralelo ou em conflito, dependendo do caso concreto. Mas talvez se deva encarar o fenômeno por outra perspectiva. Não existem propriamente duas ordens. Existe uma única ordem que se funda e se mantém na sua própria suspensão. Só existe direito e não-direito em mútua indeterminação.

Chega-se a um ponto em que é inevitável questionar o que pode ser feito a partir de constatações tão sérias. As respostas, ou, ao menos, tentativas de respostas (afinal, nem mesmo as perguntas estão perfeitamente formadas) são novamente de Agamben:

A soberania é o guardião que vela para que o limiar indecidível entre a violência e direito, natureza e linguagem não seja colocado em foco. Nós devemos ao contrário manter os olhos fixos sobre o que a estátua da justiça (que, como lembra Montesquieu, devia ser coberta no momento em que era proclamado o estado de exceção) não devia ver, o que, entretanto, é hoje claro para todos, que o estado de exceção é a regra, que a vida nua é imediatamente portadora do lugar de soberania e que, como tal, ela se encontra hoje abandonada a uma violência tão eficaz que esconde um caráter anônimo e cotidiano. ${ }^{55}$ [grifos no original]

De fato, a constatação do problema já é um começo. Ver o mundo através da lógica da exceção já põe em cheque muitas idéias há muito sedimentadas no imaginário dos juristas. Os campos mencionados muitas vezes são observados com ares de indiferença. Apesar de não perceberem que a exceção é a regra, grande parte das pessoas não se choca com esses fenômenos pois já se acostumaram com eles. São

${ }^{55}$ Tradução livre de: "La souveraineté est le gardien qui veille à ce que le seuil indécidable entre violence et droit, nature et langage ne soit pas mis en lumière. Nous devons au contraire garder les yeux fixés sur ce que la statue de la justice (qui, comme le rappelle Montesquieu, devait être voilée au moment où était proclamé l'état d'exception) ne devait pas voir, sur ce qui est aujourd'hui pourtant clair pour tous, que l'état d'exception est la règle, que la vie nue est immédiatement porteuse du lien de souveraineté et que, comme telle, elle se trouve aujourd'hui abandonnée à une violence d'autant plus efficace qu'elle revêt un caractère anonyme et quotidien". AGAMBEN, Giorgio. Le commun: comment en faire usage. Disponível em: <http://multitudes.samizdat.net/Le-commun-comment-enfaire-usage.html>. Acesso em: 2 set. 2009. 
tidos como inevitáveis. Paradoxal, mais uma vez: estar acostumado com os campos mas não perceber que eles são regra, e não "exceção".

Ver o que a estátua da justiça não deve ver é o primeiro passo para revelar o caráter anônimo e corriqueiro da violência nos campos. E o que fazer de um direito que se constitui e se mantém na sua própria suspensão?

Agamben vislumbra a possibilidade de um direito desvinculado de poder e de violência, que não é justiça, mas ao menos a porta que leva a ela. ${ }^{56}$ Talvez seja possível fazer um novo uso do direito, após a sua profanação. Profanar no sentido de restituir ao uso dos homens algo que havia sido consagrado, colocado na esfera dos deuses e fora do alcance humano. Mas o que é profanado não retorna ao estado em que se encontrava antes da consagração. Portanto, é de fato um novo uso. Porém o novo uso só pode ser criado se o velho for tornado inoperante, cancelado. ${ }^{57}$

Se o direito, conforme é usado e conhecido hoje, precisa da exceção e internaliza a violência gerada por ela, talvez a saída de Agamben seja mesmo a única, pois não será no interior desse direito que as respostas serão encontradas.

\section{REFERÊNCIAS}

AGAMBEN, Giorgio. Estado de exceção. Trad. Iraci D. Poleti. São Paulo: Boitempo, 2004.

Le commun: comment en faire usage. Disponível em: <http://multitudes.samizdat.net/Le-commun-comment-en-faire-usage.html>. Acesso em: 2 set. 2009.

\footnotetext{
${ }^{56}$ AGAMBEN. Estado de exceção ..., p. 97-98.

${ }^{57}$ Idem. Elogio da profanação. In: Profanações. Trad. Selvino J. Assmann. São Paulo:
} Boitempo, 2007. p. 65-79. 
Non au tatouage biométrique. Disponível em:

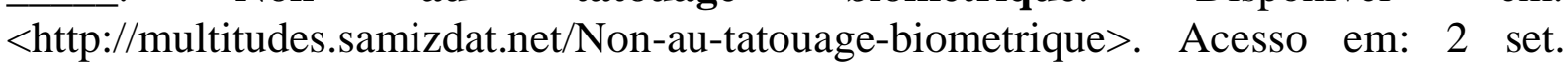
2009.

Means without end. Minneapolis: University of Minnesota Press, 2000.

O que resta de Auschwitz: o arquivo e a testemunha. Trad. Selvino J. Assmann. São Paulo: Boitempo, 2008.

. Elogio da profanação. In: Profanações. Trad. Selvino J. Assmann. São Paulo: Boitempo, 2007. p. 65-79.

BENJAMIN, Walter. Sobre o conceito de história. In: Magia e técnica, arte e política: ensaios sobre literatura e história da cultura. 4. ed. São Paulo: Brasiliense, 1985. p. 221-232.

DIKEN, Bülent; LAUSTEN, Carsten Bagge. The culture of exception: sociology facing the camp. Londres: Taylor and Francis e-library, 2005.

FREY, Klaus; DUARTE, Fábio. Auto-segregação e a gestão das cidades. Disponível em: $\quad<$ http://e-revista.unioeste.br/index.php/ccsaemperspectiva/ article/download/1422/1154>. Acesso em: 29 ago. 2009.

JULIEN-LAFFERRIÈRE, François. La rétention des étrangers aux frontières françaises. Cultures \& Conflits, 23. Disponível em: <http://www.conflits.org/index346.html>. Acesso em: 4 set. 2009. 